\title{
CAPITAL FORMATION AND ECONOMIC GROWTH UNDER CENTRAL PLANNING AND TRANSITION: A THEORETICAL AND EMPIRICAL ANALYSIS, CA. 1920-2008
}

\author{
Péter FÖLDVÁRI - Bas van LEEUWEN - Dmitry DIDENKO
}

(Received: 3 March 2014; revision received: 10 September 2014; accepted: 16 September 2014)

\begin{abstract}
According to the consensus view, it was primarily physical capital accumulation that drove economic growth during the early years of state socialism. Growth models incorporating both human and physical capital accumulation led to the conclusion that a high physical/human capital ratio can cause a lower economic growth in the long run, hence offering an explanation for the failure of socialist economies. In this paper, we show theoretically and empirically that according to the logic of the socialist planner, it was optimal to achieve a higher physical to human capital ratio in socialist countries than in the West. Using a VAR analysis, we find empirical confirmation that within the Material Product System of national accounting, the relative dominance of investment in physical capital accumulation relative to human capital was indeed more efficient than under the system of national accounts.
\end{abstract}

Keywords: Central planning, capital accumulation, human capital, Soviet Union, national accounts

JEL classification indices: E01, E22, O11, O21

The findings, interpretations, and conclusions are the authors' own views, which may not be shared by the institutions of their affiliations.

Péter Földvári, corresponding author. Postdoctoral Researcher at the Department of History and Art History, Utrecht University, Netherlands. E-mail: p.foldvari1@uu.nl

Bas van Leeuwen, Postdoctoral Researcher at the Department of History and Art History, and at the International Institute of Social History, Utrecht University, Netherlands.

E-mail: b.vanleeuwen1@gmail.com

Dmitry Didenko, Senior Analyst at the state corporation (Bank for Development and Foreign Economic Affairs) (Vnesheconombank), Russia. E-mail: didenko_d_v@veb.ru 


\section{INTRODUCTION}

The economic transition in the countries with centrally planned economies (those which identified themselves as socialist and which were often referred to in political slang as the 'Eastern Bloc' or state-socialist) has triggered many studies in its underlying sources of growth and ultimate downfall. Many of those make use of some sort of growth accounting framework in which they decompose GDP growth into the contributions by physical (or fixed) capital, human capital, and some sort of residual factor, TFP, which is assumed to capture the effects of technological change and even institutional factors. These studies often find that technical change was limited (and declining) during the socialist period and growth was mainly driven by physical capital accumulation (Kaplan 1968; Bergson 1978 [1971]: 166-168; Kontorovich 2001: 687). This view is confirmed by Allen (2003) whose simulation exercise indicates that without the massive capital accumulation of the 1930s, the USSR would have been worse off in the 1960s than it actually was. This follows logically from the neoclassical growth model (Solow 1956), which states that an increase in physical capital stock per worker increases the steady state level per capita GDP in the long run.

Yet, when compared to the Western world, actual economic growth in the 'Eastern Bloc' turned out to be much lower. Central and Eastern European countries (hereinafter referred to as CEE or Eastern Europe) and, to a lesser extent, the republics of the USSR, had been much closer to the West in the 1920s in terms of per capita income than in the 1980s (Table 1). This is consistent with studies arguing that the lack of technological advance and human capital hampered growth. Indeed, it is often found that when physical capital/human capital ratio grows, per capita GDP growth decreases (e.g. Erk et al. 1998; Duczynski 2002, 2003).

The overemphasis of physical capital accumulation is rooted in economic philosophical differences that also affected statistical standards. Former centrally planned countries measured their aggregate economic activity (or aggregate income) in terms of Net Material Product (NMP), loosely described as the sum of material production, while the West relied on the United Nation's System of National Accounts (SNA), which also includes immaterial production, mostly in the form of services. In addition, material production required more physical capital than immaterial production. Hence, in order to achieve a growth in NMP, socialist governments were more inclined to maximise material production and hence prioritise physical capital accumulation. This view was reflected by the theory of socialist reproduction embodied in the growth model voiced by the early Soviet economist Grigory Feldman (1964 [1928]): the planning priorities were defined in the way that even among material goods, productive capacities were expected to grow faster than consumer goods. In the West, on the other hand, where in- 
dividual decisions to maximise utility (usually approximated as a function of consumption) aggregate into a behaviour that can be seen as some economy level policy, the immaterial sector also took a large share of GDP and, consequently, the observed rate of physical capital accumulation was lower.

This difference in the theory of value and ways of measurement can explain why the NBER found that in the 1950s and 1960s, once Western GDP was converted into NMP (i.e. the majority of the service sector value added was subtracted), the West performed poorly in terms of economic development compared to the socialist countries. From a socialist planner's point of view it was thus logical to maximise material output and physical capital accumulation.

In this paper, we analyse economic development in Eastern Europe and the former USSR from the above outlined socialist economic policy perspective. In Section 2, we start by a basic analysis of the data. We find that most socialist countries experienced a sharply rising physical/human capital ratio combined with reducing economic growth in terms of GDP per capita. In Section 3, we provide some insights into the theoretical background and the practical implications of the socialist central planning policies. In Section 4, these insights are formalised in a one-sector model in which the government can either prefer to maximise material output or consumption (or a combination of both). This is an exogenous growth model, meaning that the long-run (balanced growth) effect is zero. This model is tested in Section 5, where we discuss some effects of physical and human capital ratio on growth. We end with a brief conclusion.

\section{DATA}

Our empirical analysis uses data on physical ${ }^{1}$ and human capital as well as GDP per capita and its closest Material Product System (MPS) equivalent NMP per capita. GDP estimates for Eastern Europe and the former USSR are taken from Maddison (2007) as updated on his website (http://www.ggdc.net/MADDISON/ oriindex.htm) and, in the case of the republics of the former USSR, extended by Didenko et al. (2013) based on the World Bank (2011). ${ }^{2}$ The physical capital stock data is taken from Van Leeuwen and Földvári (2013) for Eastern Europe and Didenko et al. (2013) for the former USSR. The latter estimate is based on gross fixed capital to GNP (at factor cost) ratio derived from Easterly - Fischer

This refers to the gross fixed capital stock.

Didenko et al. (2013) used GNP/cap, which they assumed comparable to GDP/cap, based on Bergson (1961), Becker (1969) and Steinberg (1990). 
(2001). ${ }^{3}$ The human capital stock is obtained from Didenko et al. (2013) who provide two alternative measures: the cost-and income-based stock of human capital. ${ }^{4}$ The difference between the two human capital measurements is discussed further below. NMP is taken from Didenko et al. (2013) which, in turn, was based on the official figures from 1958 to 1990 and Khanin (1991) for the earlier period. The reliability of the primary sources on the former USSR, their merits, and shortcomings are discussed by Didenko et al. (2013). The methods of construction of the time series for Eastern Europe are discussed by Van Leeuwen - Földvári (2013).

The cost-based method is based on Judson (2002), who estimates human capital by its replacement costs, relying on the public expenditure on education for a single year. We introduce only a slight modification: we multiply the replacement value of a single year of education by the average years of education in order to obtain the replacement costs of the whole educational stock of the average individual (Van Leeuwen - Földvári 2008).

$$
h_{t}=S_{t} \sum_{j} d_{j t} a_{j t}
$$

where $h_{t}$ denotes the average human capital stock per worker at the replacement cost in year $t, S_{t}$ is the average years of formal education in year $t, d_{j t}$ is the public expenditure on education per level $j$ in year $t$ (per student enrolled), $a_{j t}$ denotes the share of the labour force in year $t$ with a certain level of education.

The second method is the income-based measure suggested by Van Leeuwen - Földvári (2013). The income-based measure of human capital stock equals the present value of all future income flows under some assumptions on the expected rate of growth of real incomes, incorporating information on the average age of the population. Assuming continuous time and retirement age at 65 , the incomebased estimate of human capital can be expressed as:

3 The Soviet Economic Decline Dataset is enclosed to the World Bank electronic publication and contains the series with reference to Gomulka - Schaffer (1991) based on 'Western estimates' on GNP, labour input, and capital stock for the entire Soviet economy: Moorsteen - Powell (1966), Powell (1968), CIA (1982), CIA (various years), Kellogg (1989). The data from these underlying sources have much in common with those we use for our GNP values for the period prior to 1956 .

4 For this analysis, the cost-based analysis is the most appropriate. Not only does it compare better with the cost-based valuation of fixed capital, but also it remains a yet unanswered question of whether we can have income-based capital stock estimates for socialist economies, as generally there was just a limited market for fixed capital under socialism while there was a quasi-market for human capital. 


$$
\bar{h}=\int_{t=0}^{65-\bar{x}} \bar{w} e^{(g-q) t} d t=\frac{\bar{w}}{g-q}\left(e^{(g-q)(65-\bar{x})}-1\right)
$$

where $\bar{h}$ is per worker stock of human capital in monetary units, $\bar{w}$ is average wage, $\bar{x}$ is the average age in the population, $g$ is constant rate of expected real wage growth and $q$ is the discount factor. We assume that $q-p=0.02$, as people expect their utility resulting from higher wages will increase with time.

The results are reported in Table 1.

The most interesting feature is that there seems to be little change in per capita GDP ranking over time. Germany, Austria, and Czechoslovakia, together with the Baltic States, were as much in the top ranks in 2000 as they had been in the 1930s. The same holds true for the physical capital stock, even though the countries of the former USSR appeared to have caught up for a short time in the 1980 s. In the income-based human capital stock, we find some sort of reversal though: whereas before the World War II it was Czechoslovakia that topped the list, their places were taken by Germany and Austria after the war. The Baltic States were the most developed among the republics of the USSR both in terms of per capita GDP and income-based human capital stock. Unfortunately, we do not have comparable cost-based human capital data for Eastern Europe, but the limited data that we do have in Table 1 show a similar pattern, with the Central Asian republics and Russia dominating before the war, and the Baltic states appearing at the top of the list thereafter (although they might have been at the top of the list in the 1930s, but we unfortunately do not have any data). A possible reason may be the USSR central government equalising policy targeted at allowing the low-developed national periphery to catch up with the European Soviet regions in terms of education spread, while, at the same time, allowing the more developed Baltic republics to sustain their relatively high level. These patterns may also be observed for physical capital per capita. As shown in Table 1, even though, just as in terms of per capita GDP, Germany and Austria remained the leading economies, Russia made up quite some ground in capital formation, especially up to the 1980s. However, the political collapse in the 1990s hit the former Soviet Union area much harder than Eastern Europe and, consequently, the 1930s ranking seems to have been restored.

We report the estimates for the income-based human capital measure in Table 1 since wage data was available for all countries, while the cost-based estimation was only possible for the former USSR. As can be seen from Table 1, in terms of human capital endowment, the regional ranking differs from the ranking in physical capital. It was especially Czechoslovakia, Austria, and the Central Asian republics that did well in the 1930s. This situation remained until the 1980s, with the only difference that Germany caught up in the meantime. Yet, the collapse of 


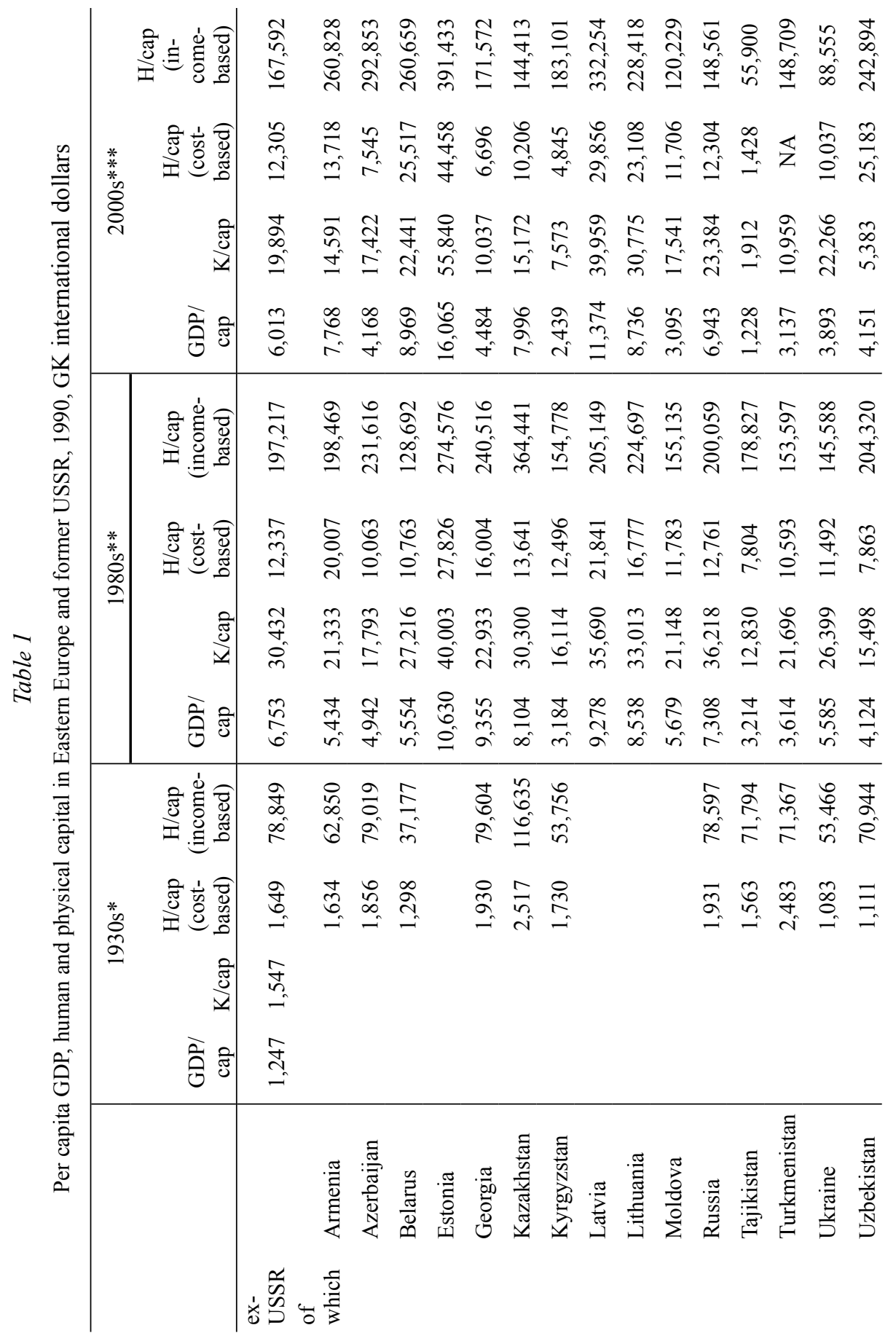




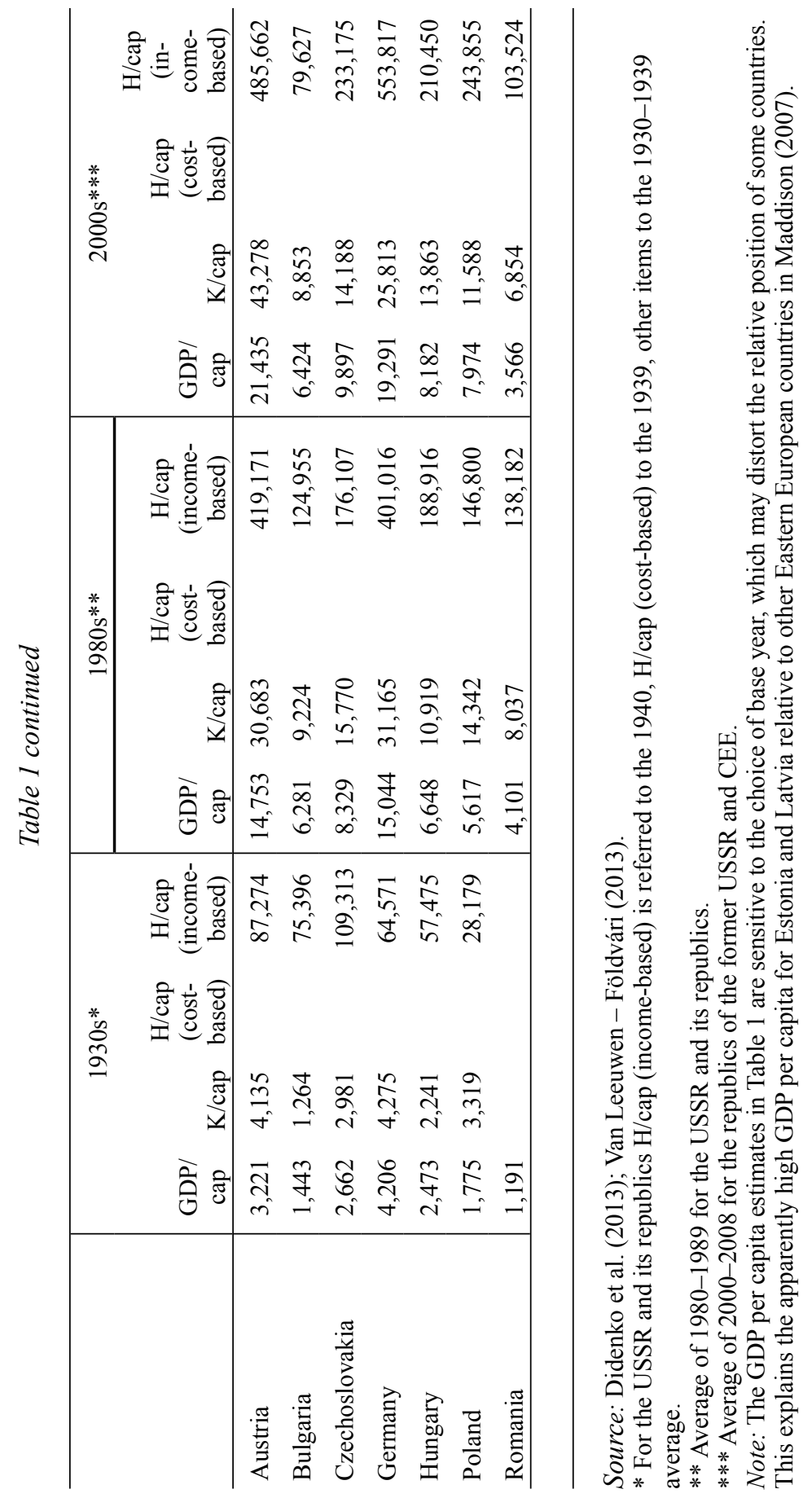


the socialist regimes completely changed this picture with Germany, Austria and the Baltic states at the head of the pack and the Central Asian republics falling far behind. This suggests that the human capital stock, when measured by the present value of earnings, especially in the Central Asian region, underwent a significant devaluation during the transition period.

In sum, whereas per capita GDP and physical capital rankings were somewhat persistent over time, this was less true for human capital. Physical capital accumulation was especially rapid in the USSR and, to a lesser extent, in Eastern Europe, but much of this ambiguous advantage was lost during the transition period. Human capital accumulation was especially rapid in Germany and Austria, and probably the Baltic states, while the initial lead of the Central Asian republics was lost during the 1990s. In other words, it seems as if the massive fixed capital accumulation had contributed both to the acceleration of growth initially (at early stages of industrialisation) and also to its deceleration at advanced stages of development (when human capital intensive service sectors were on the rise) in the socialist countries. Hence, whereas initially the gap with the Western countries in terms of per capita income seemed to be declining, after the mid-20th century, with the increase of human capital intensive economic sectors, it increased once more. The observed trends suggest that, in line with the dominant economic policy in the 'Eastern Bloc', there had been an increased accumulation of physical capital relative to human capital up to the 1980 s, but this gap was narrowed somewhat in the 1990s. This feature is plotted in Figure 1.

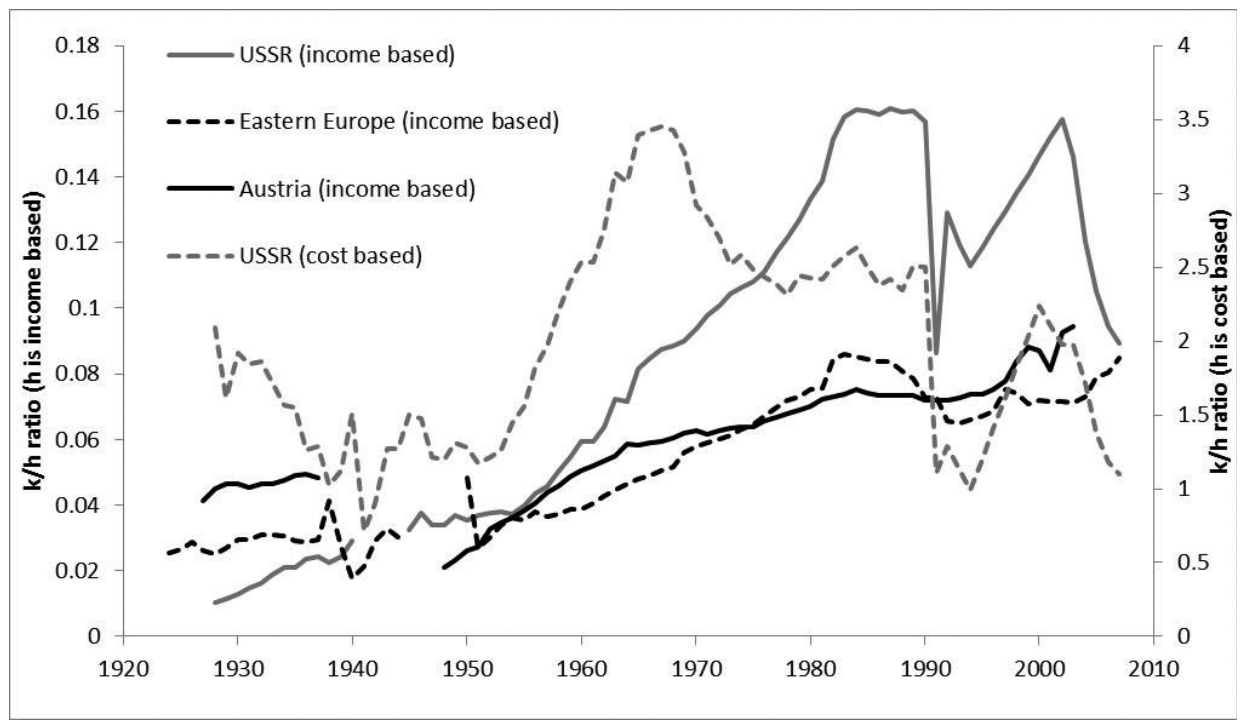

Figure 1. Physical to human capital ratio in Eastern Europe, Austria and the former USSR 
We can also observe that Eastern European dynamics were closer to the Austrian than to the Soviet one indicating that countries in Central and Eastern Europe adopted the Soviet central planning model with some modifications. Also, we find a decline of this ratio in the 1990s when market prices for physical capital were introduced and thus provided some guidance for its book values. It was logical that market prices for physical capital collapsed during the transformational restructuring of the economy. Another important point to note from Figure 1 is that the cost-based human capital indicator seems to move quite well together with the income-based measure with the exception of the pre-1940 period. Nevertheless, it is clear that both the cost- and income-based measures show a far faster growth in physical/human capital ratio in the USSR than elsewhere.

\section{THE SOCIALIST PLANNER'S PREFERENCES IN THEORY AND PRACTICE}

We find that while the ranking in terms of GDP per capita did not change much, the physical to human capital ratio increased considerably in Eastern Europe and even more in the USSR. Even though not unexpected, this observation warrants further analysis, given that some growth theories incorporating an endogenous investment in both types of capital (Caballe - Santos 1993) predict that a more physical capital intensive development path should result in a lower growth rate of per capita income. Obviously, from the perspective of a planner in a market economy, this direction would be suboptimal. But can the rationality of the economic planner in a state-socialist country be squared with the apparent overinvestment in physical capital accumulation? ${ }^{5}$ The most likely explanation lies in the different role played by the state in economic development in state-socialist countries and market economies, and, as a result, the difference in preferences of the social planner.

The idea to provide some insights into the 'socialist planner's preferences', to find some inner rationale, economic behaviour patterns, and to assess efficiency of their decisions within the socialist system's own context can be traced back to Bergson (1964). He examines to what extent their behaviour was rational to meet their ends while having expected the planners' welfare function to favour invest-

5 We prefer to call this 'apparent overinvestment' since there is no such a thing as optimal investment in absolute terms, optimality depends on preferences. A capital ratio that classifies as overinvestment from a market economy perspective may well be very rational from the point of view of a central planner with a classical (pre-marginal revolution) view on value and reproduction. 
ment and defence. Indeed, in state-socialism, initially the government takes full control of the resources and also makes the majority of allocation decisions. As such, we can use the government's priorities as those of the 'social planner'.

In a market economy, however, decisions regarding the allocation of resources are made by private agents, as they make decisions about the size and allocation of their savings and consumption. But the decisive factor is not the role of the state: even if the state has a large redistributive power (in a mixed-economy or in a welfare state), as long as its primary concern is welfare maximisation in the long run (where welfare is modelled as some function of the discounted sum of present and future consumption), the final outcome should, at least theoretically, not be different than from a society where private agents make all decisions. Form a strictly economic point of view, the possible raison d'être for a preference toward central planning could be the elimination of transaction costs and a reduction of informational asymmetry, even though it comes at the price of an additional principal-agent problem. ${ }^{6}$ In the first half of the 20th century, the idea of planning seemed quite rational and plausible to many left-wing economic and political theorists who contended to gain political power to turn it into reality.

State-socialist governments were led by the Marxian theory of economic development and economic reproduction, based on Adam Smith's view on productive and unproductive labour. Marxism motivated economic policy inherited this distinction between material and immaterial production. The latter was simply omitted from the Material Product System (MPS), the system of national account widely used in European state-socialist countries until the 1980s and in the People's Republic of China until 1993.

As the state-socialist systems emerged, it became empirically possible to study their strong and weak points. Harrison (1985) notes that two philosophies and practices of planning emerged during the late 1920s: (1) the 'balance school', whose basic idea was not to disrupt social and economic equilibrium, and to adapt capital construction to the needs of household consumption and other determinants of social welfare, and (2) the 'mobilisation school', which stressed the primary role of political decisions to get things done regardless of concomitant sacrifices, exertions, and wastes by exercise of authority, i.e. for material production. While the immediate winner in the dispute was the 'mobilisation school', the concepts of the 'balance school' were modified and incorporated into the official policy rather than rejected. As Gregory (2003) observes, the government was interested in positive incentives for the labour force that tended to abstain

6 In other words, the preferences of the central planner may be different from that of the workers, the declared "owners" of economic resources, and productive capacities in state-socialist regimes. 
from working at their margin if their wage fell below the perceived 'fair' level. The archives provide numerous expressions of the Soviet leadership's belief in a strong link between consumption and work effort: more Politburo ${ }^{7}$ time was spent on consumption (especially emergency sessions) in the 1930s than on any other issue (Gregory 2003: 94). The famine of 1932, for example, forced the authorities to temporarily allocate more resources to consumption at the expense of investments. Hence, these two approaches (balance and mobilisation) coexisted within the Soviet system as they both agreed on the need for capital accumulation to bring about rapid economic development. After each period of forced mobilisation there was need to find a temporary adjustment phase when it was possible to voice the need for restored balance as a precondition to any further mobilisation.

Even though there is a broad agreement in the literature about the principles of the planner, there is disagreement about the practical implication of these plans. Ellman (1979) stresses the decisive role of production over distribution, exchange, and consumption as the starting point of socialist planning. He also reviews how the planners considered material goods as the basis and condition of existence, and producer goods had higher priority over consumer goods. This was amplified under Stalin's rule where the balance between current needs and investments was strongly biased in favour of the latter based on a general preference for 'tomorrow' over 'today' (Nove 1983). The second branch of this literature agrees about the planner's preferences but argues that these plans were much more poorly implemented. This opinion is headed by Kornai (1992; but see also Zaleski 1980; Gregory 2003; Harrison 2005). Kornai sees the central planning system as some sort of principal-agent problem, where direct bureaucratic management is impeded by conflict of interest between the principal (who has the authority to command) and agents (who are obliged to execute the orders) as well as by information distortions. Hence, Kornai is rather sceptical whether the planners' preferences could have a strong influence on the final output structure. He argues that priorities often changed over time depending on political sentiments. Nevertheless, even with the major and minor management decisions that caused deviations from the intended policy, it is still possible to identify some fundamental policy objectives in the actual outcomes. Kornai also does not distinguish between core preferences that were shared implicitly by most of experts and decision-makers (e.g. 'current consumption is the residual of investment needs'), and particular preferences that could be campaigned but might be

The highest political organ of the ruling Communist Party in the 1930s comprised of about 10 persons that defined the political guidelines. 
subject to change (e.g., whether to rely on domestic or imported technical equipment to modernise industry).

Even though the plans were definitely inefficient in achieving their goals, the core principles behind them remained basically unchanged over time. The planning system survived for more than half a century. There were a number of priorities that were established under Stalin but had survived until the 1980s, remaining remarkably constant over time and space: investment over consumption (referring to investment-maximising mathematical growth model formulated in the late 1920 s by the above-mentioned economist, G. Feldman); industry over agriculture, while services were the least important and could be neglected; heavy industry (producer goods) over light industry (consumer goods); defence production over civilian production; domestic production over imports. Nove $(1977,1983)$ also notes that although details in the organisation of planning changed in the USSR, the planners' priorities had not been altered much. Most of these policy priorities can be found in countries that pursued a catching-up industrialisation development policy. A more prominent role played by the state in modernisation did not limit itself to state-socialist regimes, but to many late industrialisers as well, as suggested by Gerschenkron (1962). In such countries, even with fundamentally capitalist economies, the government attempted to substitute for the lack of capital and infrastructure by direct interventions. However, only in socialist countries did the state resort to commanding economic agents as regards their target output and to distributing the principal part of economic resources.

Even though mathematical methods of optimisation (linear programming, etc.) were applied to planning in the 1960-1980s, the plans never became sufficiently balanced, what was tacitly recognised even at the very top level. What really did change were the growing opportunism of the enterprises' management and their abilities to manipulate plan indicators and planners' expectations (Gregory 2003). Therefore, the plans became less ambitious and the 'balanced' approach dominated over 'mobilisation' in terms of Harrison (1985).

Both Gregory (2003), who explored the Soviet archetype, and Kornai (1992), who generalised common features of socialist systems, agree on the assertion that implicit rules and practices were exported from the Soviet Union to other planned economies. However, one should bear in mind that other socialist countries adopted the Soviet planning system in its rather modest variant. Most European satellites of the USSR entered 'socialism' at a more advanced stage of development and spent much less time under the extremely brutal forms of command management than the Soviet economy. Not acting as self-sufficient actors in global politics, they also did not have vital needs to assume a too heavy defence burden, even though their military spending remained very high relative 
to their output. Various countries' specific experience in planning is explored by Ellman (1979), Nove (1983) and many other studies. Even before the collapse of the USSR, they started to diverge from its central planning model: Yugoslavia did so almost from the start of the communist rule, Hungary after 1968, while China started reforms at the turn of the 1970s-1980s (followed by Vietnam in the late 1980s), gradually drifting to a market-based government management of the national economy.

\section{THE MODEL}

In Section 3 we claimed that while the style and objectives of planning may have changed over time, it retained the focus on material production that ultimately led to a relative overemphasis of physical capital accumulation relative to other factors of production, most notably, human capital. In this section, we use a formalised model to capture the main features of this policy. The main results and mechanisms can be summarised in a quite succinct way, however, without going into technical details. A state-socialist regime, following a Marxism-Leninisminfluenced economic policy, had a tendency to value capital goods (requiring relatively more material goods) above consumer goods (requiring a different mix of material and immaterial goods). Since material goods are likely to be produced in a more physical capital intensive way than immaterial goods, this leads to a higher ratio of physical to human capital along the optimal growth path of the economy. This has consequences for the performance of the economy as well, but the conclusion strongly depends on the way of measurement: in the SNA, since the social returns to fixed capital are likely to be lower than that of human capital (as is usually found in the empirical literature), the same amount of resources spent on increasing physical rather than human capital leads to a lower rate of economic growth. It turns out, however, that if one measures performance within the MPS, the planned economies produce a faster growth and outperform other countries. This necessarily comes at the price of reduced consumption (of both tangible and intangible goods). Once a state-socialist regime, probably thanks to growing social tensions arising from low consumption, begins to put more emphasis on the production of consumer goods relative to capital goods, its physical to human capital ratio should necessarily decline.

The optimisation problem that we discuss below is basically the same as that in Caballe - Santos (1993), also covered by Barro - Sala-i-Martin (2004, Chapter $5)$. The social planner has a combination of per capita consumption (c) and per capita material production $\left(q^{m}\right)$ in its utility function, which it seeks to maximise. 
The value function $(V)$ equals the discounted sum of the utilities over an infinite horizon:

$$
V\left(t, q^{m}, c_{t}\right)=\int_{0}^{\infty} e^{-\rho t}\left(a \ln q_{t}^{m}+b \ln c_{t}\right) d t
$$

where $\rho$ is the discount factor, $a$ and $b$ are parameters that reflect the preferences of the planner regarding material production and consumption, which we discussed in the previous section. The planner's problem is to maximise the value function.

Even though, as argued by Ellman (1973), the socialist government largely focuses on material production, we also include consumption in its utility function since the planner also wishes to prevent hunger or political instability (strong empirical evidence for this assumption is provided by Gregory 2003). As such we assume that both $a$ and $b$ are positive. Although the declared ultimate goal of the central planner was to increase the living standard (that is, consumption) in the long run, our model captures not propagandistic but actual economic policy priorities realised by the socialist planners, as highlighted in Section 3.

The factor accumulation is governed by the following equations, where, without the loss on generality, we assume the same rate of depreciation in all sectors and for both types of capital. The super- and subscripts $m$ and $i$ denote the two sectors (material and immaterial), while $k$ and $h$ denote physical and human capital, with $\delta$ and $n$ being the rate of depreciation and the growth rate of labour force, respectively. As usual, $\dot{x}=d x / d t, I$ is gross investment during period of $d t$.

$$
\begin{aligned}
& \dot{k}_{m}=I_{k}^{m}-(\delta+n) k_{m} \\
& \dot{k}_{i}=I_{k}^{i}-(\delta+n) k_{i} \\
& \dot{h}_{m}=I_{h}^{m}-(\delta+n) h_{m} \\
& \dot{h}_{i}=I_{h}^{i}-(\delta+n) h_{i}
\end{aligned}
$$

We assume that the planner seeks to spend all of its income $y$ (resources available for allocation) at time $t$, which yields the following budget constraint:

$$
y_{t}=c_{t}+I_{k}^{m}+I_{h}^{m}+I_{k}^{i}+I_{h}^{i}=k_{m}^{\beta} h_{m}^{1-\beta}+k_{i}^{\gamma} h_{i}^{1-\gamma},
$$

where $\beta$ is the elasticity between physical and human capital in material sectors and $\gamma$ is the same elasticity in immaterial sector. 
Consumption consists of material and immaterial goods, which require a different mix of the two capitals to be produced:

$$
q_{t}^{m}=k_{t}^{\beta} h_{t}^{1-\beta} \quad q_{t}^{i}=k_{t}^{\gamma} h_{t}^{1-\gamma}
$$

In equation (7) we assume that $\beta>\gamma$, that is, material goods are produced more physical capital intensively than immaterial goods.

Consumption is also modelled as a composite of the two types of goods and they are assumed to be imperfect substitutes. This is modelled as a Cobb-Douglas type function:

$$
c_{t}=\left(q_{t}^{m}\right)^{\alpha}\left(q_{t}^{i}\right)^{1-\alpha}
$$

where $\alpha$ is simply the elasticity between material and immaterial consumption.

Now we can write the following Hamiltonian ${ }^{8}$ :

$$
\begin{aligned}
& H=e^{-\rho t}\left(a \ln q_{t}^{m}+b \ln c_{t}\right)+\lambda_{1}\left(q_{t}^{m}+q_{t}^{i}-c_{t}-I_{h}^{m}-I_{k}^{i}-I_{h}^{i}-(\delta+n) k_{m}\right)+ \\
& +\lambda_{2}\left(I_{k}^{i}-(\delta+n) k_{i}\right)+\lambda_{3}\left(I_{h}^{m}-(\delta+n) h_{m}\right)+\lambda_{4}\left(I_{h}^{i}-(\delta+n) h_{i}\right)
\end{aligned}
$$

where $H$ is utility value along the optimal path and $\lambda$ is the shadow-price. ${ }^{9}$

The first order conditions for a maximum require:

$$
\begin{aligned}
& H_{c}=e^{-\rho t} \frac{b}{c_{t}}-\lambda_{1}=0, \\
& H_{I_{k}^{i}}=-\lambda_{1}+\lambda_{2}=0 \quad H_{I_{h}^{m}}=-\lambda_{1}+\lambda_{3}=0 \quad H_{I_{h}^{i}}=-\lambda_{1}+\lambda_{4}=0,
\end{aligned}
$$

or

$$
\lambda_{1}=\lambda_{2}=\lambda_{3}=\lambda_{4}=\lambda
$$

8 For econometric application of the Hamiltonian function see Barro - Sala-i-Martin (2004, A.3.3 and A.3.5).

9 The shadow price can be understood as the effect of an infinitesimally small change in the constraint on the value of the value function. Alternatively, it expresses how much the planner would be willing to pay at the optimal path for another unit of a production factor. What we find here is that at optimal path, the effect of all factors of production on the value function should be equal. 
The additional conditions of an optimal path are:

$$
\begin{aligned}
& \left.H_{k_{m}}=\frac{e^{-\rho t} \beta\left(a+\alpha b+\lambda q_{t}^{m} e^{\rho t}\right)}{k_{m}}-\lambda(\delta+n)=-\dot{\lambda}\right), \\
& H_{k_{i}}=\frac{e^{-\rho t} \gamma\left(b(1-\alpha)+\lambda q_{t}^{i} e^{\rho t}\right)}{k_{i}}-\lambda(\delta+n)=-\dot{\lambda}, \\
& H_{h_{m}}=\frac{e^{-\rho t}(1-\beta)\left(a+\alpha b+\lambda q_{t}^{m} e^{\rho t}\right)}{h_{m}}-\lambda(\delta+n)=-\dot{\lambda}, \\
& H_{h_{i}}=\frac{e^{-\rho t}(1-\gamma)\left(b(1-\alpha)+\lambda q_{t}^{i} e^{\rho t}\right)}{h_{i}}-\lambda(\delta+n)=-\dot{\lambda},
\end{aligned}
$$

where we already incorporated the condition that the shadow-prices $\lambda_{1}-\lambda_{4}$ are equal along the optimal path. Making above expressions equal for the same sectors leads to the following physical to human capital ratios within each sector:

$$
\begin{aligned}
& \frac{k_{m}}{h_{m}}=\frac{\beta}{1-\beta}, \\
& \frac{k_{i}}{h_{i}}=\frac{\gamma}{1-\gamma} .
\end{aligned}
$$

The optimal growth rate of consumption is given as follows:

$$
\begin{aligned}
& \frac{\dot{c}}{c}=\frac{e^{-\rho t} \beta\left(a+\alpha b+\lambda q_{t}^{m} e^{\rho t}\right)}{k_{m} \lambda}-(\rho+\delta+n)=\frac{\beta(a+\alpha b) c_{t}}{k_{m} b}+\left(\frac{1-\beta}{\beta}\right)^{1-\beta} e^{\rho t}-(\rho+\delta+n), \\
& \frac{\dot{c}}{c}=\frac{e^{-\rho t} \gamma\left(b(1-\alpha)+\lambda q_{t}^{i} e^{\rho t}\right)}{k_{i} \lambda}-(\rho+\delta+n)=\frac{\gamma(1-\alpha) c_{t}}{k_{i}}+\left(\frac{1-\gamma}{\gamma}\right)^{1-\gamma} e^{\rho t}-(\rho+\delta+n),
\end{aligned}
$$

where we made use of that:

$$
q_{t}^{m}=\left(\frac{1-\beta}{\beta}\right)^{1-\beta} k_{m} \text { and } q_{t}^{i}=\left(\frac{1-\gamma}{\gamma}\right)^{1-\gamma} k_{i} .
$$

Once the steady state is achieved, both per capita income and consumption will be constant. This gives us the following consumption level at steady state: 


$$
\begin{aligned}
& c_{t}=\left[\rho+\delta+n-\left(\frac{1-\beta}{\beta}\right)^{1-\beta} e^{\rho t}\right] \frac{b k_{m}}{\beta(a+\alpha b)}, \\
& c_{t}=\left(\rho+\delta+n-\left(\frac{1-\gamma}{\gamma}\right)^{1-\gamma} e^{\rho t}\right) \frac{k_{i}}{\gamma(1-\alpha)} .
\end{aligned}
$$

So the steady state ratio of the physical capital in the two sectors is:

$$
\frac{k_{m}}{k_{i}}=\frac{\rho+\delta+n-\left(\frac{1-\gamma}{\gamma}\right)^{1-\gamma} e^{\rho t}}{\rho+\delta+n-\left(\frac{1-\beta}{\beta}\right)^{1-\beta} e^{\rho t}} \frac{\beta(a+\alpha b)}{b \gamma(1-\alpha)} .
$$

The same for human capital is:

$$
\frac{h_{m}}{h_{i}}=\left[\frac{\rho+\delta+n-\left(\frac{1-\gamma}{\gamma}\right)^{1-\gamma} e^{\rho t}}{\rho+\delta+n-\left(\frac{1-\beta}{\beta}\right)^{1-\beta} e^{\rho t}}\right] \frac{(1-\beta)(a+\alpha b)}{b(1-\gamma)(1-\alpha)} .
$$

In order to arrive to the economy-wide ratios of physical to human capital, we need to express the total amount of physical and human capital in the economy:

$$
k_{t}=k_{m}+k_{i}=\left(1+\left(\frac{\rho+\delta+n-\left(\frac{1-\gamma}{\gamma}\right)^{1-\gamma} e^{\rho t}}{\rho+\delta+n-\left(\frac{1-\beta}{\beta}\right)^{1-\beta} e^{\rho t}}\right) \frac{\beta(a+\alpha b)}{b \gamma(1-\alpha)}\right) k_{i} .
$$

Doing the same for human capital yields:

$$
h_{t}=h_{m}+h_{i}=\left[1+\left(\frac{\rho+\delta+n-\left(\frac{1-\gamma}{\gamma}\right)^{1-\gamma} e^{\rho t}}{\rho+\delta+n-\left(\frac{1-\beta}{\beta}\right)^{1-\beta} e^{\rho t}}\right) \frac{(1-\beta)(a+\alpha b)}{b(1-\gamma)(1-\alpha)}\right] h_{i} .
$$


We can now simply divide the above equations and arrive at the physical to human capital ratio:

$$
\frac{k_{t}}{h_{t}}=\frac{\frac{\gamma}{1-\gamma}+\left(\frac{\rho+\delta+n-\left(\frac{1-\gamma}{\gamma}\right)^{1-\gamma} e^{\rho t}}{\rho+\delta+n-\left(\frac{1-\beta}{\beta}\right)^{1-\beta} e^{\rho t}}\right) \frac{\beta(a+\alpha b)}{b(1-\gamma)(1-\alpha)}}{1+\left(\frac{\rho+\delta+n-\left(\frac{1-\gamma}{\gamma}\right)^{1-\gamma} e^{\rho t}}{\rho+\delta+n-\left(\frac{1-\beta}{\beta}\right)^{1-\beta} e^{\rho t}}\right) \frac{(1-\beta)(a+\alpha b)}{b(1-\gamma)(1-\alpha)}} .
$$

This is a general formula when a planner derives utility both from consumption and material production. In the extreme case, when $a>0$ and $b=0$, that is, the planner does not assign any value to consumption, investment will only be in the material production and

$$
\frac{k_{t}}{h_{t}}=\frac{\beta}{1-\beta} \text {. }
$$

Since usually $\beta<0.5$, this means that $k / h<1 .{ }^{10}$

In the other extreme case, when $a=0$, we have the case where consumption is all-important (which will be approximately the case for capitalist/post-socialist countries), $b$ cancels out and we get:

$$
\frac{k_{t}}{h_{t}}=\frac{\frac{\gamma}{1-\gamma}+z \beta}{1+z(1-\beta)}=\frac{\frac{\gamma}{1-\gamma}+z \beta}{1+z-z \beta},
$$

with: $z=\left(\frac{\rho+\delta+n-\left(\frac{1-\gamma}{\gamma}\right)^{1-\gamma} e^{\rho t}}{\rho+\delta+n-\left(\frac{1-\beta}{\beta}\right)^{1-\beta} e^{\rho t}}\right) \frac{\alpha}{(1-\gamma)(1-\alpha)}>0$ and if $\beta>\gamma, \mathrm{z}>1$.

10 That is, we assume here that the proportion of capital incomes in total income is smaller than that of labour incomes. 
We take two additional special cases. If $\alpha=\beta=\theta$, that is if both material and immaterial goods were produced with the same factor intensity, the capital ratio at balanced path would be:

$$
\frac{k_{t}}{h_{t}}=\frac{\frac{\theta}{1-\theta}+\frac{\theta(a+\alpha b)}{b(1-\theta)(1-\alpha)}}{1+\frac{a+\alpha b}{b(1-\alpha)}}
$$

If additionally $a=0$, that is, the planner's utility includes only consumption:

$$
\frac{k_{t}}{h_{t}}=\frac{\theta}{1-\theta},
$$

which is the same result that Barro - Sala-i-Martin (2004, Chapter 5) obtained for a market economy. Hence, equation (33) is a special case for the more general formula for the $k / h$ ratio in equation (28) along a balanced growth path.

In the following, we choose different values of the parameters in accordance with the policy changes and simulate the physical to human capital ratios using equation (28). As we found that during the 1920s-1930s, the planner often had to give priority to consumption (Gregory 2003), in its utility function we set the coefficient values to capture this empirical evidence. We also assume that after the 1980s, with the collapse of the planned economy, the utility function of the social planner includes much less material production (i.e. $a=1$ ) since after the regime change material production is less important while consumption rises in importance. During socialist times, however, there was a preference for material production. The result is given in Figure 2 below. We have to stress that the above model incorporates human capital as direct expenditure into the model, for which the closest empirical equivalent is the cost-based measure (see Judson 2002 or Van Leeuwen - Földvári 2008). The income-based measures reflect private and social returns to human capital, so even though its trends should not deviate from the cost-based measurement for a very long period, it is much less appropriate for testing the model.

\section{EFFECTS ON ECONOMIC GROWTH}

The above simulations show that once we take the differences in the objectives of the socialist planner relative to the market economy into account, the increased focus on physical capital accumulation can be placed within the framework of rational decision. But how does this policy affect economic growth from the view- 


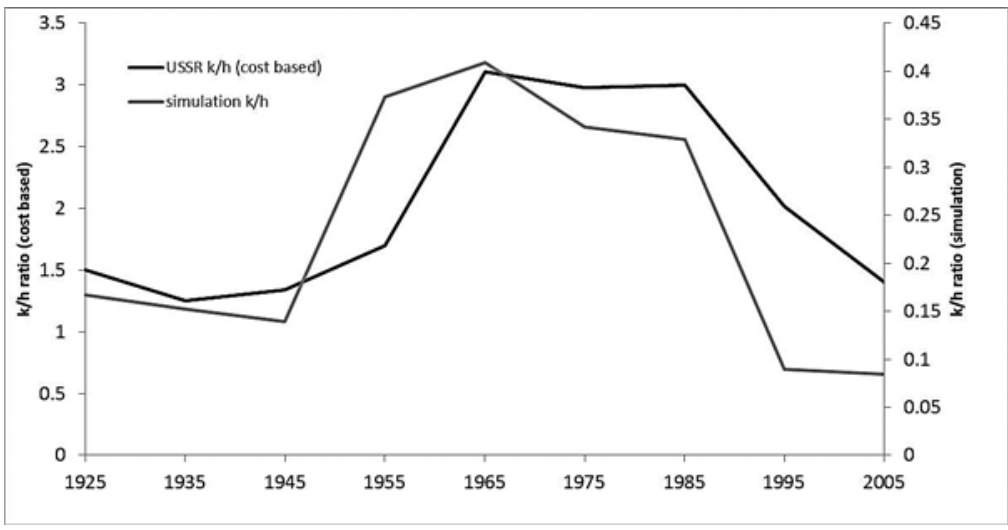

Figure 2. Simulated and actual physical to human capital ratio in the ex-USSR

Notes: Assumptions: $\rho=0.02 ; \delta=0.07 ; n=0.01$;

1920-1940: $a=1 ; b=3 ; \alpha=0.6 ; \beta=0.3 ; \gamma=0.2$;

1950s: $a=2 ; b=1 ; \alpha=0.6 ; \beta=0.4, \gamma=0.2$;

1960s: $a=3 ; b=1 ; \alpha=0.6 ; \beta=0.4, \gamma=0.2$;

1970s and 1980s: $a=2 ; b=1 ; \alpha=0.6 ; \beta=0.4, \gamma=0.2$;

1990s and 2000s: $a=0 ; b=2 ; \alpha=0.5 ; \beta=0.3, \gamma=0.2$.

point of the socialist planner? The empirical success of the strategy depends on how we measure economic growth: since the non-material sources of value added are excluded from the NMP, socialist countries are more likely to appear successful if we measure their economic activity in terms of NMP rather than in GDP.

In principle, the accumulation of any type of capital should lead to a temporary increase in economic growth, but due to their decreasing marginal product, this cannot be sustained unless the other type of capital also increases. Just like in the original model by Caballé - Santos (1993), the optimal $k / h$ ratio should remain constant along the balanced growth path unless the model parameters change fundamentally, but deviations are also possible (imbalanced growth), which should increase the growth rate relative to the balanced growth rate. ${ }^{11}$ According to our model, when aggregate economic activities are measured in terms of NMP, an increase in the $k / h$ ratio should have a greater impact on output than when GDP is used.

In order to find an empirical confirmation for this, we use the data for the USSR, for which we have a good coverage of NMP data and also cost-based human capital estimates, which are more comparable with physical capital than in-

11 If the economy has the tendency to return to the balanced growth path, this growth bonus is only temporary. 
come-based measures, and hence are more in line with the human capital concept applied in the theoretical model. We choose 1955-1989 as our sample period, which can be seen as a relatively stable period of the Soviet planned economy, after the forced industrialisation of Stalin, but before the transition to a market economy. The initial unit root tests suggest that all of our variables are stationary (Table 2).

Table 2

Unit-root tests, USSR 1955-1989 ( $p$-values in parentheses)

\begin{tabular}{l|c|c}
\hline & $\begin{array}{c}\text { ADF } \\
\text { (lag selection with MAIC) }\end{array}$ & Phillips-Perron \\
\hline $\log$ of per capita GDP & $-2.628(0.097)$ & $-3.636(0.0099)$ \\
\hline $\log$ of per capita NMP & $-5.751(0.000)$ & $-7.267(0.000)$ \\
\hline $\log$ of $k / h$ & $-6.278(0.000)$ & $-5.779(0.000)$ \\
\hline
\end{tabular}

Using these data, we estimate two vector autoregressive (VAR) systems, one with per capita GDP and the other with per capita NMP. All lag-length selection criteria suggest a VAR(1) system, but the exclusion tests suggest that a second lag still has significant explanatory power. For this reason, we estimated VAR(2) systems for both specifications. In both cases, the residuals are normally distributed and have no serial correlation significant at 5\%. Also, all the characteristic roots are found to be within the unit circle, hence the impulse-response functions (IRF) are meaningful (Figure 3).

Figure 3 reflects the reaction of the endogenous variables of the system on an innovation of one standard deviation magnitude. An initial increase in the $k / h$ ratio has an immediate negative impact on both the per capita GDP and NMP, but after 4 (NMP) or 6 (GDP) years a positive impact appears. The total effect can be
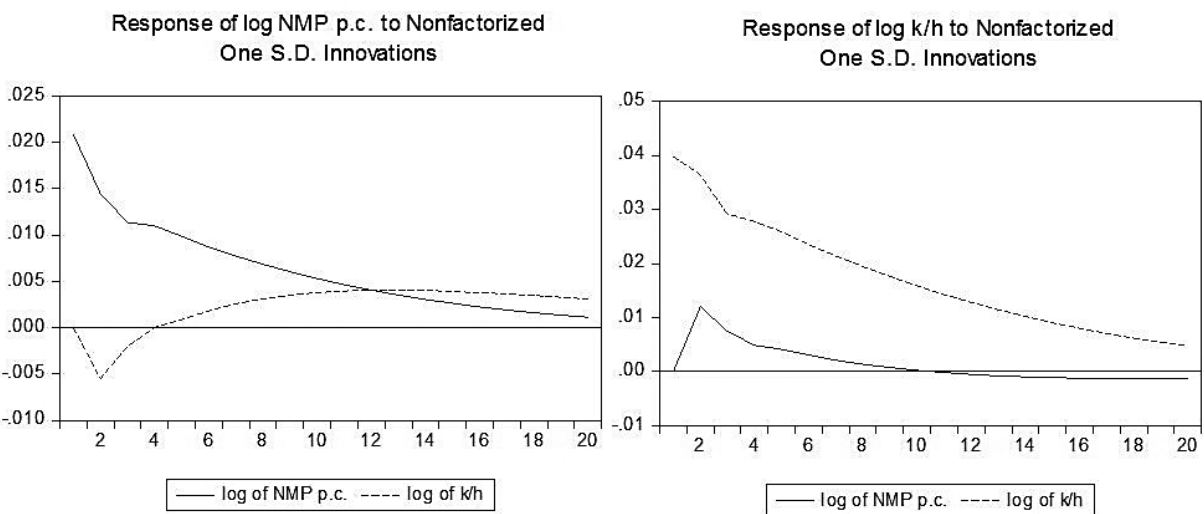

Figure 3. Impulse response functions 
estimated by looking at the accumulated responses: after 20 years a permanent one standard deviation increase in the $\log (k / h)(0.26$, i.e. about $26 \%$ increase in $k / h$ ) had an impact of $1.17 \%$ on the NMP per capita, while only $0.3 \%$ on GDP per capita. We can hence conclude that the economic policy aiming at a higher physical to human capital ratio in the USSR proved to be more efficient within the MPS than from an SNA-based point of view.

At the early stage of industrialisation (1920s-1930s), growth rates of NMP outperformed those of GNP in the USSR. They grew almost at the same rate in the 1950s, while in the 1960s-1980s growth measured by GDP was a little bit faster than by NMP. However, both rates were declining significantly. Moreover, the Soviet immaterial sector remained subdued, indicating the divergence with more advanced market economies. Clearly, GDP/GNP growth rates outperformed those of NMP at an advanced stage of industrial development and during the transition to post-industrial society when human capital intensive sectors were on the rise. In earlier stages of economic development, dominated by physical capital intensive sectors, NMP growth outperformed GDP/GNP growth. Hence, after an initial head start for NMP, GDP growth had taken the lead by the end of the century. One could expect the gap between GDP and NMP growth measures at the end of the 20th century to be wider in state-socialist countries, had their social planners and economic policy makers had more preference towards consumption and a lower physical to human capital ratio. The dynamics of both these measures during the start of transition to market economy revealed that NMP was more sensitive to adverse transformation shocks, while GDP was somewhat supported by the service sector.

\section{CONCLUSION}

There are two important observations concerning the aggregate economic performance of centrally planned economies. On the one hand, they initially experienced fast economic development due to strong capital accumulation, while, on the other hand, their growth rates declined due to a rising physical to human capital ratio $(k / h)$.

In this paper, we address these two facts in the framework of a theoretical model which allows for differences in the objective function of the social planner. State-socialist governments had preferences including both consumption and material production, while in market economies, where a central planner does not even exist, it is only consumption that can affect utility. With socialist governments having a preference for material production (Ellman 1973), due to their different understanding of value, our model predicts that state-socialist countries 
must have had a higher physical to human capital ratio $(k / h$ ratio) along the optimal growth path. This is confirmed by our empirical observations: using a VAR analysis on the USSR data, we find that while a permanent increase in the $k / h$ ratio did result in a very small, economically non-significant increase in terms of GDP per capita, once we measure value added in terms of net material product, the estimated effect increases by a factor of almost four.

Only when human capital intensive (and physical capital extensive) sectors were on the rise in the late 20th century, did an increase in the physical/human capital ratio become negative and insignificant. The fact that this applies both to capitalist and (former) socialist countries implies that even though the choices made by centrally planned economies at the start and the middle of the 20th century were both theoretically and empirically logical for the socialist planner at the time, they eventually led to a reduction in economic growth.

\section{REFERENCES}

Allen, R.C. (2003): Farm to Factory: A Reinterpretation of the Soviet Industrial Revolution. Princeton: Princeton University Press.

Barro, R. - Sala-i-Martin, X. (2004): Economic Growth. Cambridge, MA; London, England: MIT Press.

Becker, A.S. (1969): Soviet National Income, 1958-1964: National Accounts of the USSR in the Seven Year Plan Period. Berkeley: University of California Press.

Bergson, A. (1964): The Economics of Soviet Planning. New Haven: Yale University Press.

Bergson, A. (1978): Productivity and the Social System - The USSR and the West. Cambridge, MA: Harvard University Press.

Caballé, J. - Santos, M.S. (1993): On Endogenous Growth with Physical and Human Capital. Journal of Political Economy, 101(6): 1042-1067.

Didenko, D. - Földvári, P. - Van Leeuwen, B. (2013): The Spread of Human Capital in the Former Soviet Union Area in a Comparative Perspective: Exploring a New Dataset. Journal of Eurasian Studies, 4(2): 123-135, Supplementary data.

Duczynski, P. (2002): Adjustment Costs in a Two-Capital Growth Model. Journal of Economic Dynamics and Control 26(5): 837-850.

Duczynski, P. (2003): On the Empirics of the Imbalance Effect. International Journal of Business and Economics, 2(2): 121-128.

Easterly, W. - Fischer, S. (2001): The Soviet Economic Decline: Historical and Republican Data. World Bank Policy Research Working Paper, No. 1284. (Also published in the World Bank Economic Review, 9(3): 341-371, 1995).

Ellman, M. (1973): Planning Problems in the USSR. The Contribution of Mathematical Economics to Their Solution, 1960-1971. University of Cambridge Department of Applied Economics Monograph, 24.

Ellman, M. (1979): Socialist Planning. Cambridge: Cambridge University Press.

Erk, N. - Altan Cabuk, H. - Ates, S. (1998): Long-Run Growth and Physical Capital-Human Capital Concentration. Working Paper presented in International METU Conference on Economics II. (http://idari.cu.edu.tr/sanli/academic.htm). 
Feldman, G. (1964): On the Theory of Growth Rates of National Income. In: Spulber, N. (ed.): Foundations of Soviet Strategy for Economic Growth: Selected Soviet Essays, 1924-1930. pp.: 174-199 and 304-331. Bloomington: Indiana University Press. Translated from the original publication 'K teorii tempov rosta narodnogo dokhoda'. Planovoe Khoziaistvo, 1928, 11: 146170 and 12: $151-178$.

Gerschenkron, A. (1962): Economic Backwardness in Historical Perspective, a Book of Essays. Cambridge, Massachusetts: Belknap Press of Harvard University Press.

Gregory, P.R. (2003): The Political Economy of Stalinism: Evidence from the Secret Soviet Archives. Cambridge: Cambridge University Press.

Harrison, M. (1985): Soviet Planning in Peace and War, 1938-1945. Cambridge: Cambridge University Press.

Harrison, M. (2005): The Fundamental Problem of Command: Plan and Compliance in a Partially Centralised Economy. Comparative Economic Studies, 47(2): 296-314.

Judson, R. (2002): Measuring Human Capital Like Physical Capital: What Does It Tell Us? Bulletin of Economic Research 54(3): 209-231.

Kaplan, N.M. (1968): Retardation in Soviet Growth. Review of Economics and Statistics, 50(3): 293-303.

Khanin, G.I. (1991): Dinamika ekonomicheskogo razvitiia SSSR (The dynamics of the USSR economic development). Novosibirsk: Nauka, Sibirskoe otdelenie.

Kontorovich, V. (2001): Economists, Soviet Growth Slowdown and the Collapse. Europe-Asia Studies, 53(5): 675-695.

Kornai, J. (1992): The Socialist System: The Political Economy of Communism. Princeton: Princeton University Press.

Maddison, A. (2007): Contours of the World Economy, 1-2030 AD. Essays in Macro-Economic History. Oxford: Oxford University Press.

Mihályi, P. (2014): Post-Socialist Transition in a 25-Year Perspective. Acta Oeconomica, 64(S1): $1-24$.

Nove, A. (1977): The Soviet Economic System. London: George Allen \& Unwin.

Nove, A. (1983): The Economics of Feasible Socialism. London: George Allen \& Unwin.

Solow, R.M. (1956): A Contribution to the Theory of Economic Growth. Quarterly Journal of Economics, 70(1): 65-94.

Steinberg, D. (1990): The Soviet Economy 1970-1990: A Statistical Analysis. San Francisco: International Trade Press.

Van Leeuwen, B. - Földvári, P. (2008): Human Capital and Economic Growth in Asia 1890-2000: A Time-Series Analysis. Asian Economic Journal, 22(3): 225-240.

Van Leeuwen, B. - Földvári, P. (2011): Capital Accumulation and Growth in Hungary, 1924-2006. Acta Oeconomica, 61(2): 143-164.

Van Leeuwen, B. - Földvári, P. (2013): Capital Accumulation and Growth in Central Europe, 19202006. Eastern European Economics, 51(5): 69-93.

Van Leeuwen, B. - Didenko, D. - Földvári, P. (2014): Inspiration and Perspiration Factors in Economic Growth: The Former Soviet Union Area versus China (ca. 1920-2010). Economics of Transition, 23(1): 213-246.

World Bank (2011): Data by Country. http://data.worldbank.org/country (accessed 2011).

Zaleski, E. (1980): Stalinist Planning for Economic Growth, 1933-1952. Chapel Hill: The University of North Carolina Press. 